\title{
The Effect of Chronic Pancreatitis on Portal Venous Velocities
}

\author{
Artautas Mickevicius*, Habil and Jonas Valantinas \\ Vilnius University, Faculty of Medicine, Department of Gastroenterology, Hepatology and Dietetics, Lithuania
}

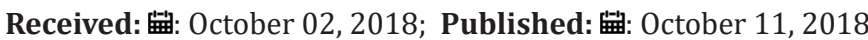

*Corresponding author: Artautas Mickevicius, Vilnius University, Faculty of Medicine, Department of Gastroenterology, Hepatology and Dietetics, Lithuania

\begin{abstract}
Introduction: Portal vein thrombosis in case of chronic pancreatitis can be induced by several interacting factors: local prothrombotic factors, endothelial damage in case of repeated acute inflammation, mechanical pressure and relatively slower venous velocities. Our aim was to assess whether chronic pancreatitis has any effect on portal vein velocities.

Materials and Methods: 35 chronic pancreatitis patients and 16 healthy individuals were included in this study, performed since 2015 to 2018 All patients were examined three times with three months intervals. During the initial examination, blood samples were taken for complete blood count, biochemical and coagulation markers, and color Doppler ultrasound performed to evaluate portal venous velocities. Ultrasound examinations were repeated later twice.
\end{abstract}

Results: Both groups were homogenous based on weight, body mass index and age. Laboratory blood test results were also insignificant, except for D-dimer concentration, which exceeded normal values in chronic pancreatitis group. Portal venous velocities did not differ between groups. Vmax and Vmean were slower in case of chronic pancreatitis, but the difference was not significant: $59 \pm 24,2 \mathrm{~cm} / \mathrm{s}$ vs $67,5 \pm 21 \mathrm{~cm} / \mathrm{s}$ in healthy controls ( $\mathrm{p}=0,554)$; and 20,8 $\pm 7,7 \mathrm{~cm} / \mathrm{s}$ vs $24,5 \pm 8,2 \mathrm{~cm} / \mathrm{s}(\mathrm{p}=0,322)$ respectively. Biochemical markers had no significant effect on portal venous velocities.

Conclusion: Chronic pancreatitis has no effect on portal venous velocities.

Keywords: Chronic Pancreatitis; Portal Vein Velocities; Thrombosis; Ultrasound

Abbreviations:CP: Chronic Pancreatitis; APPT: Activated Partial Prothrombin Time; INR: International Normalized Ratio; PT: Prothrombin Time; CRP: C-Reactive Protein; LDH: Lactate Dehydrogenase; US: Ultrasound; PVT: Portal Vein Thrombosis

\section{Introduction}

Chronic pancreatitis (CP) is a progressive chronic inflammation of pancreas with continuous fibrosis of pancreatic parenchyma that consequently deteriorates exocrine and endocrine functions of this organ and severely disturbs patients' quality of life [1,2]. Majority of CP cases, both worldwide and even more in Europe, are associated with heavy alcohol consumption, therefore longitudinal follow-up of such patients is quite complicated [3,4]. The incidence of $\mathrm{CP}$, according to various studies, varies from 4,4 to 13,4 per 100000 and the prevalence ranges from 36,9 to 41,8 cases per 100000 [5-15] Yet it is now thought that both prevalence and incidence of $\mathrm{CP}$ are higher than previously noted. As median survival in case of CP ranges from 15 to 20 years, the annual prevalence should be between 120 and 143 cases per 100000 [3]. Portal vein thrombosis (PVT), being the most common vascular disorder of the liver, is in $40 \%$ of cases associated with local factors, pancreatitis being one of them. However, pancreatitis is not very common cause of PVT, only about $13 \%$ of PVT cases are associated with pancreatitis in general [16].
According to literature, thrombotic complications are more common in case of alcohol induced, severe and necrotizing acute, and chronic pancreatitis [17-20]. Splanchnic thrombosis is diagnosed in $12-20 \%$ of patients with CP, with portal vein being obstructed less often than splenic and more often than superior mesenteric veins [21-23]. It is suggested that in case of CP, portal vein thrombosis can be induced by several interacting factors: local prothrombotic factors, damage of vascular endothelium by repeated acute inflammation, external pressure by the pancreatic pseudocyst, relatively slower venous velocities [21,24,25]. Yet, though there are both retrospective and prospective clinical studies on the obstruction of portal vein in case of chronic pancreatitis, none of them evaluated blood flow, only the fact of obstructed lumen, in case of this chronic condition [21-25]. Our aim was to assess whether chronic pancreatitis has any lasting effect on portal vein velocities thus in perspective increasing the risk of PVT. 


\section{Materials and Methods}

This prospective single centered follow-up study was performed from 2015 to 2018 in Vilnius University Hospital Santaros clinics. The local Lithuanian Bioethics Committee approved protocol of this study (No. 158200-15-774-291), and individual informed consent form was signed by each of study participants. The ethical principles of the Declaration of Helsinki for medical research involving human subjects were fulfilled [26]. 51 adult participants were enrolled in this study: 35 of them were diagnosed with $\mathrm{CP}$, and 16 were healthy controls. Hospitalized in Gastroenterology and Hepatology department to replace the stent of the common bile or pancreatic ducts, with no signs or symptoms of acute pancreatic inflammation or cholangitis at the time, $35 \mathrm{CP}$ patients were examined and portal vein velocities assessed. 16 volunteers who formed the control group were healthy individuals, with no signs or symptoms of acute or chronic pancreatitis, and no events of acute pancreatic inflammation in history. All participants with liver disease and/or its complications, myeloproliferative disorders, oncologic diseases, heart and circulatory diseases, coagulation disorders, and previous vascular disorders were excluded from the study on the basis of medical history, clinical and laboratory findings, and imaging of the liver, bile ducts, pancreas and other abdominal organs.

All patients were examined three times with three months intervals. At the time of initial examination, blood samples were collected for the laboratory tests: complete blood count, coagulation markers (activated partial prothrombin time (APPT), international normalized ratio (INR), prothrombin time (PT), fibrinogen, D-dimer), and biochemical markers (electrolytes, C-reactive protein (CRP), lipase, p-amylase and lactate dehydrogenase (LDH)). At the same day, first abdominal color Doppler ultrasound (US) was performed (Toshiba diagnostic ultrasound system, SSA-790A, Toshiba medical systems corporation, Japan) and later repeated twice during follow-up. All US examinations were performed and reviewed by the same gastroenterologist. US examination was performed for at least 6 hours starving participants, in the supine position during breath holding. The probe was applied at an insonation angle smaller than $60^{\circ}$ in the middle part of the vessels. The main portal vein was assessed about 2 centimeters from the junction between the splenic and superior mesenteric veins. Left and right portal veins were measured 1-2 centimeters from their branching.

Each time, all abdominal organs were evaluated: liver, spleen, pancreas, as well as major hepatic vessels. Diameter, patency, and main measurements and indices of portal veins were evaluated: Vmax (maximum systolic blood flow velocity); Vpeak (peak systolic velocity); Vmin (minimal systolic velocity); Vmean (mean velocity); PI (pulsatility index); RI (resistivity index). All indices were measured three-times during each examination and arithmetical mean calculated for the most accurate result. Vmax, Vmean and RI were the measures that were used in statistical analysis and comparisons. Data handling and analysis were performed with SPSS version 12.0 software (SPSS Inc., Chicago, IL). Quantitative variables are expressed as the mean ( \pm standard deviation), or median and range, and qualitative variables as absolute and relative frequencies. Comparisons between groups of quantitative and qualitative variables were made by the Wilcoxon and chi square tests, respectively. All tests were two-sided, and $p<0,05$ was considered significant.

\section{Results}

Demographic characteristics of all participants are presented in Table 138 (74,5\%) men and 13 (25,5\%) women participated in the study, aged 25 to 64 years. Both groups were homogenous based on the weight, body mass index and age $(p>0,05)$, and only gender structure differed significantly. Alcohol was the main etiological factor in CP group comprising 65,7\% of all cases, others were of biliary origin. Blood tests showed significant inflammatory changes in CP group compared to healthy controls, nonetheless, in both groups, white blood cell count and relative neutrophil count were within normal limits: $9 \pm 3,4 \times 109 / 1$ vs $5,7 \pm 0,8 \times 109 / 1$ $(\mathrm{p}<0,001)$ and $56,9 \pm 2,9 \%$ vs $52,2 \pm 7,4 \%(\mathrm{p}=0,005)$ respectively. Pancreatic enzymes were within normal limits in both groups $(p>0$, $05)$, however other biochemical markers: fibrinogen, D-dimers, CRP and LDH differed significantly: 4,6 $\pm 1,4 \mathrm{mg} / \mathrm{l} \mathrm{vs} 2,8 \pm 0,5 \mathrm{mg} / \mathrm{l}$ ( $\mathrm{p}<0,001) ; 899,4 \pm 1503,5 \mathrm{mcg} / \mathrm{l}$ vs $136,6 \pm 58,1 \mathrm{mcg} / \mathrm{l}(\mathrm{p}=0,003) ;$ $36,5 \pm 55,9 \mathrm{mg} / \mathrm{l}$ vs $0,7 \pm 0,7 \mathrm{mg} / \mathrm{l}(\mathrm{p}<0,001) ; 198,6 \pm 51,6 \mathrm{mg} / \mathrm{l}$ vs $168,5 \pm 22,2 \mathrm{mg} / \mathrm{l}(\mathrm{p}=0,021)$. Nevertheless, only D-dimer exceeded normal limits in CP group, other values were within normal limits of hospital laboratory in both groups. APTT, PT and INR did not differ between groups.

Table 1: Demographic characteristics.

\begin{tabular}{|c|c|c|c|}
\hline & $\begin{array}{c}\text { CP group } \\
n=35(68,6 \%)\end{array}$ & $\begin{array}{l}\text { Control group } \\
n=16(31,4 \%)\end{array}$ & $\begin{array}{c}P \\
\text { value }\end{array}$ \\
\hline \multicolumn{4}{|l|}{ Gender; n (\%) } \\
\hline Male & $30(85,7 \%)$ & $8(50 \%)$ & \multirow{2}{*}{0,032} \\
\hline Female & $5(14,3 \%)$ & $8(50 \%)$ & \\
\hline Age, years; M, (range) & $45,5(32-64)$ & $42,7(25-63)$ & 0,472 \\
\hline Weight, kg; M, (range) & $72,6(52-102)$ & $74,8(56-102)$ & 0,640 \\
\hline Height, cm; M, (range) & $175,9(160-190)$ & $\begin{array}{c}176,7(164- \\
190)\end{array}$ & 0,730 \\
\hline BMI; M, (range) & $23,5(17,6-36)$ & $23,8(19,2-30,1)$ & 0,783 \\
\hline
\end{tabular}

All portal veins were completely patent during all US examinations in both study groups. Portal vein velocities did not differ significantly between two groups. Neither at the initial examination nor later, during the second or third follow-ups did velocities differ between the groups. As all three examinations were insignificant, presented further are only initial measurements and their correlation to laboratory findings. Vmax was statistically significantly similar when comparing results of healthy controls and LP patients: $67,5 \pm 21 \mathrm{~cm} / \mathrm{s}$ vs $59 \pm 24,2 \mathrm{~cm} / \mathrm{s}(\mathrm{p}=0,554)$ in main portal vein, $44 \pm 23,8 \mathrm{~cm} / \mathrm{s}$ vs $39,1 \pm 19,1 \mathrm{~cm} / \mathrm{s}(\mathrm{p}=0,660)$ in right portal vein; and $20 \pm 7,3 \mathrm{~cm} / \mathrm{s}$ vs $21,2 \pm 9,2 \mathrm{~cm} / \mathrm{s}(\mathrm{p}=0,876)$ in left portal vein (Figure 1). Vmax did not change in CP group during all follow-up period as well. Though instantly comparing Vmean was lower in CP group, the difference was not significant between groups either: $20,8 \pm 7,7 \mathrm{~cm} / \mathrm{s}$ in CP group vs $24,5 \pm 8,2 \mathrm{~cm} / \mathrm{s}$ in control group ( $\mathrm{p}=0,322)$ in the main portal vein; $14,5 \pm 7 \mathrm{~cm} / \mathrm{s}$ vs 
$16,4 \pm 8,1 \mathrm{~cm} / \mathrm{s}(\mathrm{p}=0,715)$ in right portal vein; and 7,2 $\pm 2,7 \mathrm{~cm} / \mathrm{s}$ vs $7,4 \pm 2,5 \mathrm{~cm} / \mathrm{s}(\mathrm{p}=0,698)$ in left portal vein (Figure 2).

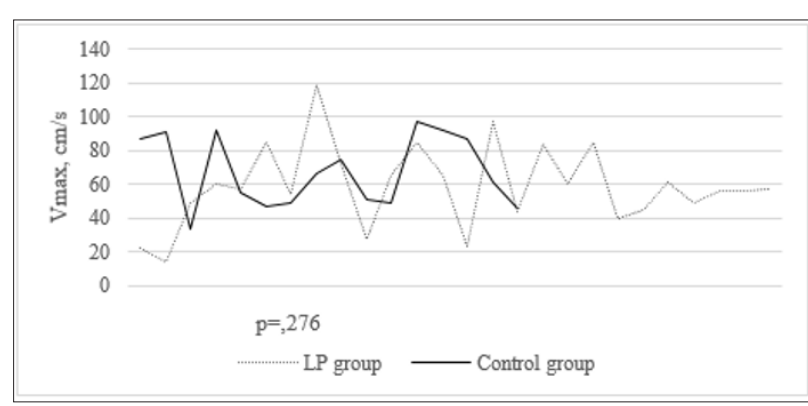

Figure 1: Vmax of the main portal vein during first US examination.

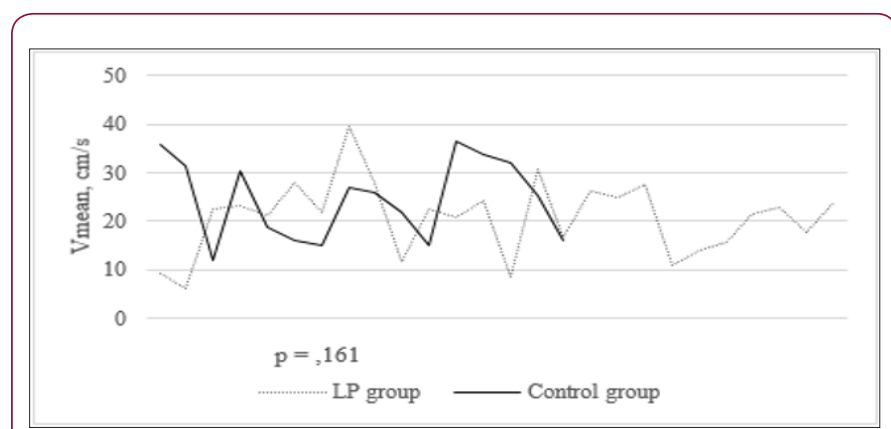

Figure 2: V mean of the main portal vein during first US examination.

No significant changes in Vmean were noticed during followup visits as well. Other indices - PI or RI did not differ neither between groups nor between all three examinations. Portal venous velocities did not correlate with demographic factors: gender, body mass index (BMI), and age. It was not significantly influenced by any of complete blood count parameters. CRP, fibrinogen and LDH, values of which differed significantly between two study groups, did not correlate with portal venous velocities as well (Figure 3). Though exceeding normal ranges, D-dimer had no effect on blood flow changes in CP group (Figure 3).

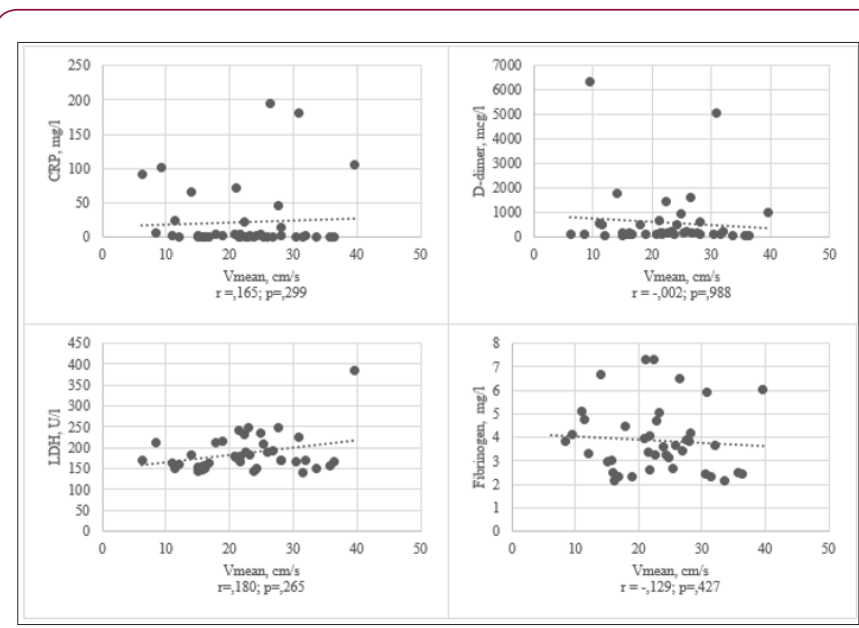

Figure 3: Correlation between biochemical markers and $\mathrm{V}$ mean of main portal vein.

\section{Discussion}

Though it was expected that over the time CP affects portal vein velocities and decreases the blood flow thus initiating obstruction of the lumen, based on our results, it has no significant effect on blood flow in portal system. During our follow-up period, not one case of thrombosis was observed. The biggest limitation here, of course, is small study sample - knowing the fact that PVT is quite rare in case of CP [21-23], it is not surprising we did not observe portal vein obstruction during our study time. Nonetheless, velocities showed no tendency toward reduced blood flow and increased risk of PVT. According to our results, both Vmax and Vmean of main portal vein, its right and left branches were slower compared to healthy same aged individuals, however this difference was not significant, and the difference did not change during the follow-up period. In a study of $266 \mathrm{CP}$ patients, who were repeatedly examined for thrombus, the incidence of PVT was 5,6\%, and acute pancreatitis and caudal pseudocysts were the probable cause of spleno-portal vein obstruction in $91,4 \%$ of all cases [27].

Several other authors also stressed the effect of acute inflammation and mechanic pressure of pancreatic cysts on the development of PVT in case of CP [25]. In our study, were purposely excluded patients with cysts in pancreas and acute inflammation to evaluate the effect of chronic process only. We also aimed to find the relationship between biochemical markers and portal venous velocities. However, as no significant differences between study groups were observed comparing velocities, laboratory parameters were of no significant value as well. The only one to differ significantly and exceed the normal limits was D-dimer. A recent study (Zhang et al.) showed higher than $240 \mathrm{mcg} / \mathrm{l}$ concentration of D-dimer was highly sensitive (100\%) and had negative prognostic value when excluding PVT [28]. What is more, increased D-dimer concentration is associated with higher risk of venous thrombosis $[29,30]$.

\section{Acknowledgement}

Consent to publish. We warrant that the article is the authors' original work. We warrant that the article has not received prior publication and is not under consideration for publication elsewhere. All authors agree for the article to be published Availability of Data and Materials. All the data supporting findings are owned by the authors and can be given by the corresponding author under the request by an email.

\section{References}

1. Machicado JD, Chari ST, Timmons L, Tang G, Yadav D (2018) A populationbased evaluation of the natural history of chronic pancreatitis. Pancreatology 18(1): 39-45.

2. Talamini G, Bassi C, Butturini G (2001) Outcome and quality of life in chronic pancreatitis. JOP 2: 117-123.

3. Levy P, Dominguez-Munoz E, Imrie C, Lohr M, Maisonneuve P (2014) Epidemiology of chronic pancreatitis: burden of the disease and consequences. United European Gastroenterol J 2(5): 345-354.

4. Otsuki M (2003) Chronic pancreatitis in Japan: Epidemiology, prognosis, diagnostic criteria, and future problems. J Gastroenterol 38: 315-326.

5. Lankisch PG, Assmus C, Maisonneuve P, Lowenfels AB (2002) Epidemiology of pancreatic diseases in Lüneburg County. A study in a 
defined German population. Pancreatol Off J Int Assoc Pancreatol IAP Al 2(5): 469-477.

6. Díte P, Starý K, Novotný I, Precechtelová M, Dolina J, et al. (2001) Incidence of chronic pancreatitis in the Czech Republic. Eur J Gastroenterol Hepatol 13(6): 749-750.

7. Yadav D, Timmons L, Benson JT, Dierkhising RA, Chari ST, et al. (2011) Incidence, prevalence, and survival of chronic pancreatitis: a populationbased study. Am J Gastroenterol 106(12): 2192-2199.

8. Lin Y, Tamakoshi A, Matsuno S, Takeda K, Hayakawa T, et al. (2000) Nationwide epidemiological survey of chronic pancreatitis in Japan. J Gastroenterol 35(2): 136-141.

9. Tinto A, Lloyd DJ, Kang JY, Majeed A, Ellis C, et al. (2002) Acute and chronic pancreatitis--diseases on the rise: a study of hospital admissions in England 1989/90-1999/2000. Aliment Pharmacol Ther 16(12): 2097-2105.

10. Yang AL, Vadhavkar S, Singh G, Omary MB (2008) Epidemiology of alcohol-related liver and pancreatic disease in the United States. Arch Intern Med 168(6): 649-656.

11. Spanier BWM, Dijkgraaf MGW, Bruno MJ (2008) Trends and forecasts of hospital admissions for acute and chronic pancreatitis in the Netherlands. Eur J Gastroenterol Hepatol 20(7): 653-658.

12. Yadav D, Muddana V, O'Connell M (2011) Hospitalizations for chronic pancreatitis in Allegheny County, Pennsylvania, USA. Pancreatol Off J Int Assoc Pancreatol IAP Al 11(6): 546-552.

13. Hu C, Wen L, Deng L, Zhang C, Lugea A, et al. (2017) The Differential Role of Human Cationic Trypsinogen ( PRSS1 ) p.R122H Mutation in Hereditary and Nonhereditary Chronic Pancreatitis: A Systematic Review and Meta-Analysis. Gastroenterol Res Pract 2017: 1-7.

14. Majumder S, Chari ST (2016) Chronic pancreatitis. The Lancet 387(10031): 1957-1966.

15. Rasch S, Valantiene I, Mickevicius A, Beer S, Rosendahl J, et al. (2016) Chronic pancreatitis: Do serum biomarkers provide an association with an inflammageing phenotype? Pancreatology 16(5): 708-714.

16. Thatipelli MR, McBane RD, Hodge DO, Wysijubsju WE (2010) Survival and Recurrence in Patients With Splanchnic Vein Thromboses. Clin Gastroenterol Hepatol 8(2): 200-205.

17. Park WS, Kim HI, Jeon BJ, Kim SH, Lee SO (2012) Should anticoagulant be administered for portal vein thrombosis associated with acute pancreatitis? World J Gastroenterol 18(42): 6168-6171.

18. Mortele KJ, Mergo PJ, Taylor HM, Wiesner W, Cantisani V, et al. (2004) Peripancreatic vascular abnormalities cimplicating acute pancreatitis: contrast-enhanced helical CT findings. Eur J Radiol 52(1): 67-72.

\section{ISSN: 2574-1241}

\section{DOI: 10.26717/BJSTR.2018.10.001881}

Artautas Mickevicius. Biomed J Sci \& Tech Res

This work is licensed under Creative Commons Attribution 4.0 License

Submission Link: https://biomedres.us/submit-manuscript.php
19. Gonzelez HJ, Sahay SJ, Samadi B, Davidson BR, Rahman SH, et al. (2011) Splanchnic vein thrombosis in severe acute pancreatitis: a 2-year, single0instittuion experience. HPB 13(12): 860-864.

20. Zhou J, Ke L, Tong Z, Li G, Li W, et al. (2015) Risk factors and outcome of splanchnic venous thrombosis in patients with necrotizins acute pancreatitis. Thromb Res 135(1): 68-72.

21. Agarwal AK, Kumar KR, Agarwal S, Singh S (2008) Significance of splenic vein thrombosis in chronic pancreatitis. Am J Surg 196(2): 149-154.

22. Butler JR, Eckert GJ, Zyromski NJ, Leonardi MJ, Lillemoe KD, et al. (2011) Natural history of pancreatitis-induced splenic vein thrombosis: a systematic review and meta-analysis of its incidence and rate of gastrointestinal bleeding. HPB 13(12): 839-845.

23. Xu W, Qi X, Chen J, Su C, Guo X (2015) Prevalence of splanchnic vein thrombosis in pancreatitis: a systematic review and meta-analysis of observational studies. Gastroenterol Res Pract 2015: 1-23.

24. Sakorafas GH, Tsiotou AG (1999) Splenic-vein thrombosis complicatin chronic pancreatitis. Scand J Gastroenterol 34(12): 1171-1177.

25. Rebours V, Boudaoud L, Vullierme MP, Vidaud D, Condat B, et al. (2012) Extrahepatic portal venous systemic thrombosis in recurrent acute and chronic alcoholic pancreatitis is caused by local inflammation and not thrombophilia. Am J Gastroenterol 107(10): 1579-1585.

26. WMA - The World Medical Association - WMA Declaration of Helsinki Ethical Principles for Medical Research Involving human Subjects.

27. Bernades P, Baetz A, Levy P, Belghiti J, Menu Y, et al. (1992) Splenic and portal venous obstruction in chronic pancreatitis: A prospective longitudinal study of a medical-surgical series of 266 patients. Dig Dis Sci 37(3): 340-346.

28. Zhang DL, Hao JY, Yang N (2013) Value of D-dimer and protein S for diagnosis of portal vein thrombosis in patients with liver cirrhosis. J Int Med Res 41(3): 664-672.

29. Qi X, Li H, Guo X, Dai J (2015) Role of D-dimer in the Development of Portal Vein Thrombosis in Liver Cirrhosis: A Meta-analysis. Saudi J Gastroenterol 21(3): 165.

30. Van Hylckama Vlieg A, Baglin CA, Luddington R, MacDonald S, Rosendaal FR, et al. (2015) The risk of a first and a recurrent venous thrombosis associated with an elevated D-dimer level and an elevated thrombin potential: results of the THE-VTE study. J Thromb Haemost 13(9): 16421652.

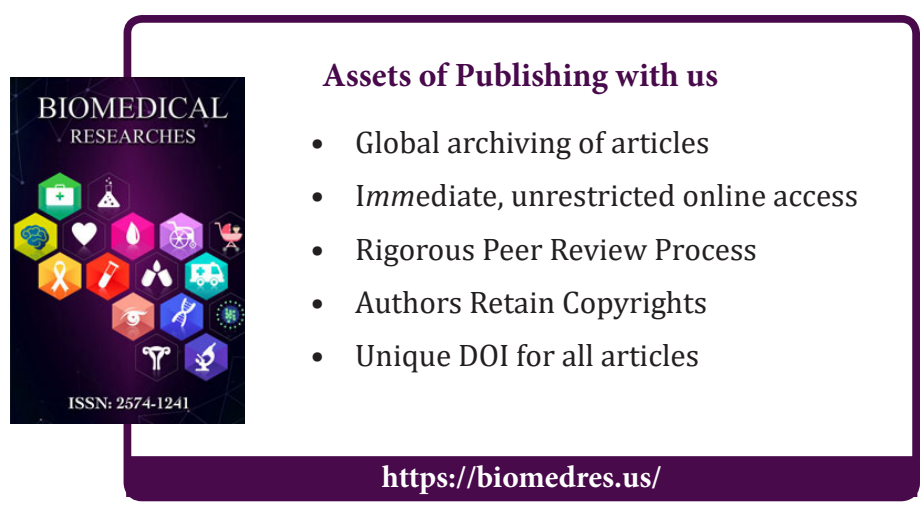

Cite this article: Artautas Mickevicius, Habil, Jonas Valantinas. The Effect of Chronic Pancreatitis on Portal Venous Velocities. Biomed J

Sci\&Tech Res 10(1)-2018. BJSTR. MS.ID.001881. DOI: 10.26717/ BJSTR.2018.10.001881. 